\title{
A retrospective study of changes of histopathology of nasal polyps in adult Chinese in central China*
}

\author{
Wen-Xiu Jiang 1,2,\#, Ping-Ping Cao 1, \#, Zhi-Yong Li', Guan-Ting Zhai', Bo Liao', \\ Xiang Lu', Zheng Liu' \\ 'Department of Otolaryngology - Head and Neck Surgery, Tongji Hospital, Tongji Medical College, Huazhong University of \\ Science and Technology, Wuhan, P.R. China \\ 2 Department of Otolaryngology - Head and Neck Surgery, Affiliated Eye, Ear, Nose and Throat Hospital, Fudan University, \\ Shanghai, China
}

Rhinology 57: 4, 261 - 267, 2019

https://doi.org/10.4193/Rhin18.070

*Received for publication:

April 2, 2018

Accepted: January 2, 2019

\# These authors contributed equally

Background: The factors contributing to the eosinophilic inflammation in chronic rhinosinusitis with nasal polyps (CRSwNP) remain elusive. This study was designed to investigate the inflammatory patterns and tissue remodeling of CRSwNP in patients from central China at two time points over 14 years apart and the influence of age.

Methods: One hundred and eight CRSwNP patients enrolled in 2000 and 2001 (group A), and 134 CRSwNP patients enrolled in 2014 and 2015 (group B) were retrospectively studied. Hematoxylin-eosin stained tissue sections were used to study characteristics of inflammation and tissue remodeling. Immunohistochemistry was used to further evaluate the cells positive for eosinophil cationic protein (ECP), IL-5, IgE, tryptase or myeloperoxidase (MPO). Time- and age-related difference was analyzed.

Results: The number of eosinophils and proportion of eosinophilic CRSwNP were increased, whereas the numbers of total inflammatory cells and lymphocytes were decreased in group B as compared with group A. Group B had severer epithelial squamous metaplasia and basement membrane thickening, and a lower number of mucosal glands than group A. Higher numbers of ECP+,

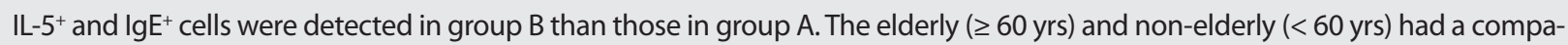
rable number of eosinophils and ratio of eosinophilic CRSwNP.

Conclusion: Eosinophilic inflammation has been significantly augmented over time, which is associated with increased Th2 response and IgE production, and accompanied by exaggerated epithelium remodeling in CRSwNP patients from central China. Age has no significant influence on eosinophilic inflammation.

Key words: chronic rhinosinusitis, eosinophil, histopathology, inflammation, nasal polyps

\section{Introduction}

Although eosinophilic inflammation is a cardinal feature of chronic rhinosinusitis with nasal polyps (CRSwNP) in Western countries $^{(1,2)}$, a significant percentage of CRSwNP patients in East Asian countries including China, Korea, and Japan do not demonstrate obvious eosinophilic inflammation ${ }^{(3-5)}$. Particularly, studies directly comparing patients from Western countries and China have revealed less eosinophilic inflammation in Chinese patients ${ }^{(6-8)}$.

The reasons underlying different patterns of inflammation between Asian and Caucasian patients are unclear. Recently, a study reported lower eosinophilia and a reduced proportion of eosinophilic CRSwNP in US second-generation Asian patients as compared with African American and Caucasian American patients, suggesting a potential genetic regulation of eosinophilia ${ }^{(9)}$. On the other hand, three studies comparing CRSwNP in different periods of time in Korean and Thai patients interestingly showed that there was a trend of increase of eosinophil infiltration and proportion of eosinophilic type in CRSwNP over time ${ }^{(10-12)}$, indicating an involvement of environmental factors in the development of eosinophilic inflammation in CRSwNP. However, two of the three reported studies included not only adult patients but also non-adult patients ${ }^{(10,11)}$, and one study enrolled patients with unilateral disease ${ }^{(12)}$, which might bias 
the results. Moreover, the studies on Thai and Korean population reported conflicting results on the neutrophilic inflammation in CRSwNP over time ${ }^{(10,11)}$. Although Chinese CRSwNP patients also demonstrate less eosinophilic and more neutrophilic inflammation compared with Caucasian patients ${ }^{(7,8)}$, whether there are histopathological changes over time in Chinese has not been studied yet. In addition to the changes in inflammation patterns, whether there is a change in tissue remodeling over time in Chinese patients with CRSwNP has not been investigated either. Recent studies have demonstrated a potential influence of age on the airway inflammation. Cho and collaborators suggested that eosinophilic inflammation may subside with age in patients with CRSwNP ${ }^{(13)}$. While, Kim and collaborators reported that the elderly had a lower number of neutrophils compared with the non-elderly in patients with non-eosinophilic CRSwNP, and no significant difference in inflammation between elderly and non-elderly was found in patients with eosinophilic CRSwNP (14). Those inconsistent findings argue for further investigation of the influence of age on the inflammation in patients with CRSwNP.

The purposes of the current study were:

1) to investigate the change of inflammatory patterns as well as tissue remodeling over time in adult patients with CRSWNP in central China, and

2) to investigate whether there is an age-related difference and whether it varies along with time in patients with CRSwNP in central China.

\section{Material and Methods}

\section{Subjects}

This study was approved by the Ethics Committee of Tongji Medical College of Huazhong University of Science and Technology, Wuhan, China, and conducted with written informed consent from patients. The diagnosis of CRSwNP was made according to the current European EAACI Position Paper on Rhinosinusitis and Nasal Polyps ${ }^{(2)}$. The atopic status was evaluated by skin prick test to a panel of aeroallergens common in our region. The diagnosis of asthma and aspirin sensitivity was based on history and physician diagnosis. All patients were over 18 years and had bilateral nasal polyps (NP). Subjects who had antrochoanal polyps, cystic fibrosis, fungal sinusitis, vasculitis, or primary ciliary dyskinesia were excluded. All the patients received sinus surgery after failure of medical treatment. Patients did not receive systemic glucocorticoids or intranasal steroids within 1 month before surgery. Since surgical trauma may lead to tissue remodeling and alter histology, patients with previous surgical history for CRS were also excluded in the present study. NP specimens were collected during surgery. To include samples separated by the longest possible time period, specimens from 2000 and 2001, which were the earliest with complete clinical information, and specimens from 2014 and 2015 were selected and analyzed.

\section{Histologic analysis}

NP tissue sections $(5 \mu \mathrm{m})$ were stained with hematoxylin-eosin (HE). The HE-stained sections were observed by 2 independent investigators who were blind to the clinical data. The numbers of eosinophils, neutrophils, plasma cells, lymphocytes, and total inflammatory cells in the lamina propria (LP) per high power field (HPF) ( $\times 400)$ and the number of glands per low power field (LPF) $(\times 100)$ were counted. Ten fields were randomly selected and the average number per field was analyzed. The number of goblet cells, squamous metaplasia of epithelium, and the thickness of the basement membrane were also evaluated. For the count of goblet cells, three sites containing intact epithelium were randomly selected and the results were expressed as cells per $100 \mu \mathrm{m}$ of the epithelium. Squamous metaplasia was screened under low power magnification and confirmed under high power magnification. Squamous metaplasia of epithelium was assessed and semi-quantitatively scored ( 1 = not present-focal, $2=$ mild, $3=$ moderate, and $4=$ marked) as described previously (10). Basement membrane thickness was measured with the graticule accessory to the microscope under high power magnification, and the results were expressed as microns $(\mu \mathrm{m})$. Ten locations were randomly selected and the average value was calculated. In case of disagreement (the values from 2 independent investigators differed by $>10 \%$ ), a consensus was reached by reviewing the specimen at a multi-head microscope by our research team. NPs were defined as eosinophilic when the average percent eosinophils exceeded $10 \%$ of total inflammatory cells as defined by our previous study ${ }^{(3)}$. The cut-off was calculated as twice the SD of the mean of eosinophil percentage in controls ${ }^{(3)}$. In addition, the severity of stromal edema and fibrosis was evaluated under low power magnification. Stromal edema and stromal fibrosis were semi-quantitatively scored into categorical variables $(1=$ not present-focal, $2=$ mild, $3=$ moderate, and $4=$ marked) as previous study described ${ }^{(10)}$.

\section{Immunohistochemistry}

For immunohistochemistry, after deparaffinization and rehydration, sections were subjected to heat-induced antigen retrieval using Target Retrieval Solution (Dako, Carpinteria, CA, USA). The 3\% hydrogen peroxidase was used to inhibit endogenous peroxidase and $5 \%$ bovine serum albumin was used to block non-specific binding. Sections were incubated with mouse monoclonal antibody against tryptase (1:200, Abcam, Cambridge, UK), or rabbit polyclonal antibody against lgE (working solution, Abcam), eosinophil cationic protein (ECP; 1:100, Boster Biotechnology, Wuhan, China), myeloperoxidase (MPO; 1:100, Zhongshan Golden Bridge Biotechnology, Beijing, China), or IL-5 (1:200, Boosen Biotechnology, Beijing, China). All antigens were detected by using the poly-horseradish peroxidase complex method and color development was achieved with 3', 3'-diaminobenzidine. The number of positive cells per HPF was analyzed. 
Table 1. The demographic characteristics of patients.

\begin{tabular}{|lccc|}
\hline & Group A & Group B & $\begin{array}{c}\text { P } \\
\text { value }\end{array}$ \\
\hline Subject, n & 108 & 134 & $/$ \\
\hline Sex, male, n (\%) & $79(73.1 \%)$ & $91(67.9 \%)$ & NS \\
\hline Disease duration (y), median (IQR) & $5(1.0,10)$ & $4.5(0.5,9)$ & NS \\
\hline Age (y), median (IQR) & $42(30,53)$ & $49(31,63)$ & $<0.05$ \\
\hline Elderly patient, n (\%) & $14(13.0 \%)$ & $42(31.3 \%)$ & $<0.01$ \\
\hline Patients with atopy, n (\%) & $24(22.2 \%)$ & $40(29.9 \%)$ & NS \\
\hline Patients with asthma, n (\%) & $4(4 \%)$ & $8(6 \%)$ & NS \\
\hline Patients with smoking habit & $26(24 \%)$ & $29(21.6 \%)$ & NS \\
\hline
\end{tabular}

The demographic features of patients with CRSwNP in both group $A$ and $B$ were displayed and compared. The elderly is defined as the age $\geq 60$ years; IQR, interquartile range; NS, Not significant.

Five HPFs were randomly selected and analyzed by 2 independent observers.

\section{Statistical analysis}

For continuous variables, results were expressed as medians and interquartile ranges. The Mann-Whitney $U$ 2-tailed test was used for between-group comparison. Differences in proportions between groups were analyzed by the chi-square test. The Spearman test was used to determine correlations. Significance was accepted at $\mathrm{P}<0.05$.

\section{Results}

\section{Subjects}

The demographic and clinical characteristics of patients are displayed in Table 1. Two-hundred and forty-two adult CRSwNP patients with complete clinical information undergoing primary endoscopic sinus surgery were enrolled in this study, including 108 patients receiving surgery during 2000 and 2001 (group A) and 134 patients receiving surgery during 2014 and 2015 (group B). The two groups were comparable in gender distribution and disease duration; however, patients in group $B$ were older than patients in group $A$ (Table 1). The prevalence of atopy and asthma and the smoking rate were similar in both groups. None of the patients had aspirin sensitivity in both groups based on history. We further divided patients into elderly ( $\geq 60 \mathrm{yrs}$ ) and non-elderly (<60yrs) groups as previously described ${ }^{(13)}$. The elderly population accounted for $13.0 \%$ and $31.3 \%$ of the subjects in group $A$ and group $B$, respectively. A higher proportion of the elderly was found in group $B$ than in group $A$ (Table 1 ).

\section{Histology results}

The number of tissue eosinophils was significantly higher in group B compared to group A (Table 2). Consistently, a higher
Table 2. Histologic characteristics in group A and B.

\begin{tabular}{|c|c|c|c|}
\hline & Group A & Group B & P value \\
\hline $\begin{array}{l}\text { Subjects with eosinophilic } \\
\text { CRSwNP, n (\%) }\end{array}$ & $\begin{array}{c}17 \\
(15.7 \%)\end{array}$ & $\begin{array}{c}59 \\
(44 \%)\end{array}$ & $<0.01$ \\
\hline $\begin{array}{l}\text { Eosinophil, } \\
\text { median (IQR) }\end{array}$ & $\begin{array}{c}1.1 \\
(0.4,3.0)\end{array}$ & $\begin{array}{c}3.4 \\
(1.1,14.6)\end{array}$ & $<0.01$ \\
\hline $\begin{array}{l}\text { Neutrophil, } \\
\text { median (IQR) }\end{array}$ & $\begin{array}{c}3.0 \\
(0,15)\end{array}$ & $\begin{array}{c}2.2 \\
(0,10.1)\end{array}$ & NS \\
\hline $\begin{array}{l}\text { Lymphocyte, } \\
\text { median (IQR) }\end{array}$ & $\begin{array}{c}37.7 \\
(27.4,50.2)\end{array}$ & $\begin{array}{c}22.3 \\
(12.4,38.6)\end{array}$ & $<0.01$ \\
\hline $\begin{array}{l}\text { Plasma cell, } \\
\text { median (IQR) }\end{array}$ & $\begin{array}{c}4.7 \\
(2.5,7.6)\end{array}$ & $\begin{array}{c}4.1 \\
(2.2,7.0)\end{array}$ & NS \\
\hline $\begin{array}{l}\text { Total inflammatory cell, } \\
\text { median (IQR) }\end{array}$ & $\begin{array}{c}49.7 \\
(37.1,64.5)\end{array}$ & $\begin{array}{c}40.5 \\
(26.9,57.1)\end{array}$ & $<0.01$ \\
\hline $\begin{array}{l}\text { Goblet cell, } \\
\text { median (IQR) }\end{array}$ & $\begin{array}{c}3.3 \\
(2.4,4.6)\end{array}$ & $\begin{array}{c}2.7 \\
(1.5,4.3)\end{array}$ & NS \\
\hline $\begin{array}{l}\text { Squamous metaplasia } \\
\text { score, median (IQR) }\end{array}$ & $\begin{array}{c}0.4 \\
(0,0.8)\end{array}$ & $\begin{array}{c}0.8 \\
(0.4,1.6)\end{array}$ & $<0.01$ \\
\hline $\begin{array}{l}\text { BM thickness, } \\
\text { median (IQR) }\end{array}$ & $\begin{array}{c}10.5 \\
(6.7,19.1)\end{array}$ & $\begin{array}{c}24.8 \\
(14.8,41.2)\end{array}$ & $<0.01$ \\
\hline $\begin{array}{l}\text { Mucosal gland, } \\
\text { median (IQR) }\end{array}$ & $\begin{array}{c}11.8 \\
(4.3,20.1)\end{array}$ & $\begin{array}{c}4.5 \\
(0.2,16.9)\end{array}$ & $<0.01$ \\
\hline $\begin{array}{l}\text { Tissue edema score, } \\
\text { median (IQR) }\end{array}$ & $\begin{array}{c}1.8 \\
(1.2,2.4)\end{array}$ & $\begin{array}{c}1.7 \\
(1,2.2)\end{array}$ & NS \\
\hline $\begin{array}{l}\text { Tissue fibrosis score, } \\
\text { median (IQR) }\end{array}$ & $\begin{array}{c}0.9 \\
(0.2,1.6)\end{array}$ & $\begin{array}{c}0.8 \\
(0.4,1.3)\end{array}$ & NS \\
\hline
\end{tabular}

Histologic characteristics of patients with CRSwNP in group A and $B$ were displayed and compared. The results of inflammatory cells are expressed as cells per high power field; the number of glands is expressed as glands per low power field; the number of goblet cells is expressed as goblet cells per $100 \mu \mathrm{m}$ epithelium; the unit of measurement for the thickness of basement membrane (BM) is $\mu \mathrm{m}$; IQR, interquartile range; NS, Not significant.

proportion of eosinophilic CRSwNP (44\%) was found in group $B$ than in group $A(15.7 \%)$ (Table 2). In contrast, the numbers of total inflammatory cells and lymphocytes in group B were significantly decreased in comparison with those in group A. Notably, the numbers of neutrophils and plasma cells were comparable in both groups (Table 2).

As regard to tissue remodeling, the number of goblet cells was comparable between the 2 groups (Table 2). However, squamous metaplasia of epithelium was more frequently observed and basement membrane was thicker in group $B$ than those in group A (Table 2). In contrast, the number of mucosal glands was decreased in group $B$ compared with group $A$. No significant difference in stromal edema and fibrosis was revealed between group $A$ and group $B$ (Table 2). Positive correlations were found between tissue eosinophilia and the severity of epithelial squamous metaplasia $(r=0.247, P<0.001)$ and basement membrane thickness $(r=0.312, P<0.001)$. 
Table 3. Histological characteristics in elderly and non-elderly.

\begin{tabular}{|lccccccc} 
& & Group A & & & \multicolumn{2}{c}{ Group B } \\
\hline & Elderly & Non-elderly & P value & Elderly & Non-elderly & P value \\
\hline Subject, $n$ (\% in the whole group) & $14(13.0 \%)$ & $94(87.0 \%)$ & $/$ & $42(31.3 \%)$ & $92(68.7 \%)$ & $/$ \\
\hline Subject with eosinophilic CRSwNP, $n$ (\%) & $3(21.4 \%)$ & $14(14.9 \%)$ & NS & $20(47.6 \%)$ & $39(42.4 \%)$ & NS \\
\hline Eosinophil, median (IQR) & $0.50(0.3,3.2)$ & $1.3(0.5,2.9)$ & NS & $4.3(1.3,17.2)$ & $3.0(1.1,11.4)$ & NS \\
\hline Neutrophil, median (IQR) & $1.5(1.0,4.5)$ & $3.8(0.8,16.2)$ & NS & $2.2(0,7.5)$ & $3.1(0,10.1)$ & NS \\
\hline Lymphocyte, median (IQR) & $32.8(25.4,58.7)$ & $38.3(29.1,48.9)$ & NS & $20.1(11.9,27.8)$ & $26.3(15.8,40.0)$ & $<0.05$ \\
\hline Plasma cell, median (IQR) & $4.9(1.8,6.7)$ & $4.6(2.6,7.6)$ & NS & $3.0(1.9,6.0)$ & $4.6(2.5,7.3)$ & NS \\
\hline Total inflammatory cell, median (IQR) & $50.9(34.7,51.3)$ & $49.7(39.1,62.9)$ & NS & $37.5(24.7,51.7)$ & $45(30.0,59.3)$ & NS \\
\hline Goblet cell, median (IQR) & $3.4(2.8,4.5)$ & $3.3(2.4,4.7)$ & NS & $2.7(1.6,4.2)$ & $2.6(1.5,3.9)$ & NS \\
\hline Squamous metaplasia score, median(IQR) & $0.4(0.2,0.6)$ & $0.4(0,0.8)$ & NS & $1.0(0.4,1.6)$ & $0.8(0.4,1.7)$ & NS \\
\hline BM thickness, median(IQR) & $8.6(6.4,35.5)$ & $10.6(6.7,18.3)$ & NS & $26.2(15.5,50.4)$ & $24.8(15.2,37.6)$ & NS \\
\hline Mucosal gland, median(IQR) & $10.2(5.0,23.4)$ & $12.4(4.2,18.3)$ & NS & $3.9(0.2,11.9)$ & $6.3(0.4,21)$ & NS \\
\hline Tissue edema score,median(IQR) & $1.6(1.2,2.4)$ & $1.8(1.3,2.4)$ & NS & $2.0(1.3,2.6)$ & $1.6(1.0,2.0)$ & $<0.05$ \\
\hline Tissue fibrosisscore,median(IQR) & $0.6(0,1.4)$ & $1.0(0.2,1.6)$ & NS & $0.6(0.2,1.2)$ & $0.8(0.4,1.4)$ & NS \\
\hline
\end{tabular}

Histological features of elderly and non-elderly patients with CRSwNP in both group A and group B were displayed and compared. The elderly is defined as the age $\geq 60$ years; the results for the inflammatory cells are expressed as cells per high power field; the number of glands is expressed as glands per low power field, the number of goblet cells is expressed as goblet cells per $100 \mu m$ epithelium, the unit of measurement for the thickness of basement membrane is $\mu \mathrm{m}$; IQR, interquartile range; NS, Not significant.

Given the difference in the age of patients between the two groups and previously reported influence of age on inflammation ${ }^{(13)}$, we next investigated the potential influence of age on the histological features. We subgrouped patients into elderly and non-elderly. As shown in Table 3, we did not find a significant difference in inflammation or tissue remodeling between elderly and non-elderly patients in both groups except that the elderly in group B had less lymphocyte infiltration and severer edema compared with non-elderly in the same group.

\section{Immunohistochemistry results}

To further explore the change of inflammation patterns in CRSwNP over time, we did immunohistochemistry study for some important molecules and cells in some patients $(n=20$ for each group). In line with the findings of HE staining study, we found that the number of ECP+ eosinophils was significantly increased in group B compared to group A (Table 4). Moreover, the numbers of IL-5 $5^{+}$cells and $\lg \mathrm{E}^{+}$cells were significantly higher in group B compared to group A (Table 4). However, no difference in tryptase ${ }^{+}$mast cells was discovered for the two groups. Again, similar to the findings of HE staining, we failed to find any difference in the number of $\mathrm{MPO}^{+}$neutrophils between the two groups (Table 4). Interestingly, we found that the number of $\lg \mathrm{E}^{+}$ cells positively correlated with the number of $\mathrm{ECP}^{+}$cells in group $B(r=0.481, P=0.032)$. We did not find any associations between age and the numbers of $\mathrm{ECP}^{+}$eosinophils $(r=-0.072, \mathrm{P}=0.762)$,
IL-5 cells $(r=0.061, P=0.806)$, Ig $E^{+}$cells $(r=-0.317, P=0.270)$, tryptase $\mathrm{e}^{+}$mast cells $(\mathrm{r}=0.173, \mathrm{P}=0.478)$ or $\mathrm{MPO}^{+}$neutrophils $(r$ $=-0.254, P=0.294)$.

\section{The impact of atopy on the inflammatory patterns of CRSwNP}

To explore whether atopy status having an impact on the inflammatory patterns of CRSwNP, patients were stratified into atopic and non-atopic CRSwNP and compared. Higher numbers of eosinophils, IL-5+ cells, and $\lg \mathrm{E}^{+}$cells were observed in atopic CRSwNP vs non-atopic CRSwNP in both group A [for eosinophils, atopic vs non-atopic CRSwNP: $3.4(2.5,4.7)$ vs $1.2(0.9,2.1)$, $\mathrm{P}<0.05$; for IL-5+ cells, atopic vs non-atopic CRSwNP: 9.1 (6.9, 11.2) vs $7.0(5.9,8.5) \mathrm{P}<0.05$; for $\mathrm{lgE}^{+}$cells, atopic vs non-atopic CRSwNP: $9.5(7.2,14.3)$ vs $6.6(4.7,8.8) P<0.05$ ] and B [for eosinophils, atopic vs non-atopic CRSwNP: $4.7(3.0,6.9)$ vs 2.3 (1.9, 5,4), P < 0.05; for IL-5+ cells, atopic vs non-atopic CRSwNP: 16.8 $(10.3,19.7)$ vs $10.6(8.0,14.0), P<0.05$; for lgE $E^{+}$cells, atopic vs non-atopic CRSwNP: 12.7 (9.6, 14.8) vs 10.1 (8.2, 11.0), $\mathrm{P}<0.05]$. However, when we compared non-atopic patients in group $A$ and $B$, we still observed significantly increased proportion of eosinophilic CRSwNP (group B vs group A: $39.4 \%$ vs $10.7 \%, P<$ 0.05 ) and the numbers of eosinophils, IL- $5^{+}$cells, and $\lg \mathrm{E}^{+}$cells in group $B$ compared with group $A$ [for eosinophils, group $A$ vs group $B: 1.2(0.9,2.1)$ vs $2.3(1.9,5.4), P<0.05$; for IL-5+ cells, group A vs group B: $7.0(5.9,8.5)$ vs $10.6(8.0,14.0), \mathrm{P}<0.05$; for 
Table 4. Immunohistochemistry analysis in group A and B.

\begin{tabular}{|c|c|c|c|}
\hline & Group A & Group B & $P$ value \\
\hline $\begin{array}{l}\text { ECP+ eosinophil, } \\
\text { median (IQR) }\end{array}$ & $\begin{array}{c}5.4 \\
(3.6,7.7)\end{array}$ & $\begin{array}{c}9.6 \\
(7.6,12)\end{array}$ & $<0.05$ \\
\hline $\begin{array}{l}\text { IL-5+ cell, } \\
\text { median (IQR) }\end{array}$ & $\begin{array}{c}6.2 \\
(4.1,10.1)\end{array}$ & $\begin{array}{c}17.7 \\
(13.6,19)\end{array}$ & $<0.05$ \\
\hline $\begin{array}{l}\text { IgE' cell, } \\
\text { median (IQR) }\end{array}$ & $\begin{array}{c}7.8 \\
(7.1,9)\end{array}$ & $\begin{array}{c}12 \\
(11.8,14.3)\end{array}$ & $<0.01$ \\
\hline $\begin{array}{l}\mathrm{MPO}^{+} \text {neutrophil, } \\
\text { median (IQR) }\end{array}$ & $\begin{array}{c}15 \\
(12.5,20)\end{array}$ & $\begin{array}{c}11.3 \\
(8.3,18.3)\end{array}$ & NS \\
\hline $\begin{array}{l}\text { Tryptase }{ }^{+} \text {mast cell, } \\
\text { median (IQR) }\end{array}$ & $\begin{array}{c}7 \\
(4.2,8)\end{array}$ & $\begin{array}{c}6.6 \\
(4.4,7.6)\end{array}$ & NS \\
\hline
\end{tabular}

The counts of $\mathrm{ECP}^{+}, \mathrm{IL}^{-} 5^{+}, \mathrm{lgE} \mathrm{E}^{+}, \mathrm{MPO}^{+}$and tryptase ${ }^{+}$cells in both group $\mathrm{A}$ and $\mathrm{B}$. Results of the $\mathrm{ECP}^{+}, \mathrm{IL}-5^{+}, \mathrm{IgE}^{+}, \mathrm{MPO}^{+}$or tryptase ${ }^{+}$cells are expressed as numbers per high power field of lamina propria; IQR, interquartile range; NS, Not significant.

$\lg \mathrm{E}^{+}$cells, group A vs group B: $6.6(4.7,8.8)$ vs $10.1(8.2,11.0), \mathrm{P}<$ 0.05)].

\section{Discussion}

The present study was designed to evaluate the change in inflammatory patterns and tissue remodeling of NPs in the same geographical area in China over time. All subjects enrolled were adult patients with bilateral NPs. Consistent with previous findings in other Asian countries ${ }^{(10,11)}$, a significant increase of eosinophilic inflammation was identified in patients with CRSwNP in central China over a 14-year period, which may relate to up-regulated Th2 reactions and local lgE in NPs and is accompanied by exaggerated epithelium remodeling.

Atopic status has been reported to be associated with tissue eosinophilia and increased levels of Th2 cytokines and IgE in patients with CRSwNP in western China ${ }^{(15)}$. In the present study, we also found that the atopic CRSwNP had a significantly increased number of eosinophils, IL- $5^{+}$cells, and IgE $^{+}$cells compared with non-atopic CRSwNP in both group A and B. Nevertheless, in non-atopic patients, we still observed an increased proportion of eosinophilic CRSwNP and the numbers of eosinophils, IL-5+ cells, and $\lg \mathrm{E}^{+}$cells in group $B$ compared with group $A$, indicating that atopy is unlikely a determining factor for the augmented eosinophilic inflammation over time in patients with CRSwNP in central China.

In Caucasian patients with CRSwNP, Staphylococcus aureus enterotoxins have been suggested, acting as both antigens and superantigens, to drive local IgE production and eosinophilic inflammation ${ }^{(16)}$. We previously demonstrated that local lgE, more likely induced by common aeroallergens, may contribute to eosinophilic inflammation in Chinese patients with nasal polyps ${ }^{(17)}$. In this study, we found that lg $\mathrm{E}^{+}$cells were increased in group $\mathrm{B}$ and correlated with $\mathrm{ECP}+$ eosinophils, suggesting a role of local lgE in driving the change of eosinophilic inflammation in Chinese CRSwNP patients over time. The factors leading to the increase of IgE in CRSwNP over time in Chinese patients are currently unclear. Intramucosal Staphylococcus aureus has been indicated as a factor contributing to the shift from neutrophilic to eosinophilic inflammation patterns in Thai CRSwNP patients (11). However, previous studies only detected the immunoreaction to Staphylococcus aureus in a small portion of Chinese patients with CRSwNP, even in eosinophilic type, disfavoring a role of Staphylococcus aureus in inducing lgE in Chinese patients $(8,17,18)$. Very recently, IgE antibodies against Streptococcus pyogenes and Haemophilus influenzae were detected and reported in Japanese patients with eosinophilic CRSwNP (19). Therefore, the role of bacteria or common aeroallergens in the change of local $\lg$ E in NPs deserves further studies.

In line with a previous study ${ }^{(10)}$, lymphocytes infiltration in patients with CRSwNP was significantly decreased over time. In addition, we found that the number of total inflammatory cells was also decreased in Chinese patients with CRSwNP. The significance of those changes and the underlying mechanisms are interesting topics to be studied in the future. Kim et al. found neutrophils infiltration decreased over time in Korean CRSwNP patients ${ }^{(10)}$, on the contrary, Katotomichelakis et al. reported neutrophils increased over time in Thai CRSwNP patients ${ }^{(11)}$. In this study, by using both $\mathrm{HE}$ and immunohistochemical staining, we demonstrated that there was no significant change of neutrophilic inflammation in Chinese patients with CRSwNP over time.

We demonstrated an increase of squamous metaplasia and basement membrane thickening over time in Chinese patients with CRSwNP, which may be explained by the potential link between tissue eosinophilia and epithelial damage and basement membrane thickness ${ }^{(20)}$. Consistent with a previous study ${ }^{(10)}$, the number of glands was decreased over a 14-year period. Positive correlations between edema and eosinophilic inflammation, and between fibrosis and neutrophilic inflammation in CRS have been suggested previously ${ }^{(21)}$. Although both Thai and Korean patients with CRSwNP displayed an increase of eosinophilic inflammation over time, more severe edema was only reported in Thai patients with CRSWNP ${ }^{(10,11)}$. In the present study, we did not find a significant change in edema in Chinese patients with CRSwNP either. Those discrepancies might be related to the relatively rough and subjective quantification method applied to evaluate edema and fibrosis. A more precise and objective quantification method is better to be developed and used for edema and fibrosis evaluation in the future. There is controversy regarding the influence of age on the inflammation patterns of patients with CRSwNP ${ }^{(11,13,14)}$. Combining HE staining with immunohistochemistry, we did not find a significant influence of age on eosinophilic or neutrophilic inflam- 
mation in Chinese patients with CRSwNP, which also excluded the possibility that the difference in eosinophilic inflammation between two groups was due to the age difference. Some limitations of this study must be addressed. First, it's a retrospective study. We did not have data of symptom scores, CT and endoscopic scores. We, therefore, cannot fully exclude the impact of different disease severity on the results. Secondly, all the subjects in this study were from central China, which may impair the generalizability of our findings. In addition, there have been some changes in the management of CRSwNP over the last 15 years based on more insights into the pathogenesis of chronic rhinosinusitis. In this study, we found that the percentage of patients who had a history of corticosteroid use in group $B$ was higher compared with that in group $A$, which might have somewhat influences on the inflammatory patterns of CRSwNP, especially in group B. However, all the patients enrolled in this study stopped use of glucocorticoids within 1 month before surgery. Furthermore, glucocorticoids are effective in inhibiting Th2 responses and eosinophilic inflammation, which further supports the notion that eosinophilic inflammation has been enhanced over a 14-year period in Chinese patients with CRSWNP.

\section{Conclusion}

Through comparing NP samples obtained over a 14-year period, our current study replicates the increase of eosinophilic inflammation in CRSwNP over time in Chinese patients, which is associated with up-regulated Th2 response and local IgE and accompanied by the epithelium remodeling. Age has no significant impact on eosinophilic and neutrophilic inflammation in Chinese patients with CRSwNP. These findings implicate the importance of environmental factors in regulating eosinophilia in Chinese CRSwNP, although the involvement of other factors including genetic influence cannot be excluded.

\section{Acknowledgements}

Grant Support: This study was supported by the National Natural Science Foundation of China (NSFC) grants 81325006, 81570899, 81630024 (Z.L.), 81670911 (X.L.) and 81400449 (P.P.C), and Hubei Province Natural Science Foundation grant 2017 CFA016 (Z.L.).

\section{Authorship contribution}

Study idea and design: XL,ZL; Sample screening and collection: ZYL, BL; experiment and data analysis: WXJ, PPC, GTZ; manuscript: WXJ, PPC, XL; critical review of the manuscript: ZL; final approval: all authors.

\section{Conflict of interest}

The authors declare that no conflict of interest exists.

\section{References}

1. Meltzer EO, Hamilos DL, Hadley JA, et al. Rhinosinusitis: Establishing definitions for clinical research and patient care. J Allergy Clin Immunol 2004;114:155-212.

2. Fokkens WJ, Lund VJ, Mullol J, et al European position paper on rhinosinusitis and nasal polyps 2012. Rhinol Suppl 2012;23:1-298.

3. Cao PP, Li HB, Wang BF, et al. Distinct immunopathologic characteristics of various types of chronic rhinosinusitis in adult Chinese. J Allergy Clin Immunol 2009; 124:478-484.

4. Kim JW, Hong SL, Kim YK, Lee CH, Min YG, Rhee CS. Histological and immunological features of non-eosinophilic nasal polyps. Otolaryngol Head Neck Surg 2007;137:925930.

5. Ishitoya J, Sakuma $Y$, Tsukuda M. Eosinophilic chronic rhinosinusitis in Japan. Allergol Int 2010;59:239-245.

6. Bachert C, Zhang N, Holtappels G, et al. Presence of IL-5 protein and IgE antibodies to staphylococcal enterotoxins in nasal polyps is associated with comorbid asthma. J Allergy Clin Immunol 2010;126:962-968.

7. Zhang N, Van Zele T, Perez-Novo C et al. Different types of T-effector cells orchestrate mucosal inflammation in chronic sinus disease. J Allergy Clin Immunol 2008;122:961-968.
8. Wang $X$, Zhang N, Bo M, et al. Diversity of $\mathrm{TH}$ cytokine profiles in patients with chronic rhinosinusitis: A multicenter study in Europe, Asia, and Oceania. J Allergy Clin Immunol 2016;138:1344-1353.

9. Mahdavinia M, Suh LA, Carter RG, et al Increased noneosinophilic nasal polyps in chronic rhinosinusitis in US second-generation Asians suggest genetic regulation of eosinophilia. J Allergy Clin Immunol 2015;135:576-579.

10. Kim SJ, Lee KH, Kim SW, Cho JS, Park YK, Shin SY. Changes in histological features of nasal polyps in a Korean population over a 17-year period. Otolaryngol Head Neck Surg 2013;149:431-437.

11. Katotomichelakis M, Tantilipikorn P Holtappels G, et al. Inflammatory patterns in upper airway disease in the same geographical area may change over time. Am J Rhinol Allergy 2013;27:354-360.

12. Shin SH, Ye MK, Kim JK, Cho CH. Histological characteristics of chronic rhinosinusitis with nasal polyps: recent 10-year experience of a single center in Daegu, Korea. Am J Rhinol Allergy 2014;28:95-98.

13. Cho SH, Hong SJ, Han B, et al. Age-related differences in the pathogenesis of chronic rhinosinusitis. J Allergy Clin Immunol 2012;129:858-860.

14. Kim DW, Kim DK, Jo A, et al. Age-related decline of neutrophilic inflammation is associated with better postoperative prognosis in non-eosinophilic nasal polyps. Plos One 2016;11:e0148442

15. Ba L, Du J, Liu F, et al. Distinct inflammatory profiles in atopic and nonatopic patients with chronic rhinosinusitis accompanied by nasal polyps in western China. Allergy Asthma Immunol Res 2015;7:346-358.

16. Bachert C, Gevaert P, Holtappels G, Johansson SG, van Cauwenberge P. Total and specific lgE in nasal polyps is related to local eosinophilic inflammation. J Allergy Clin Immunol 2001;107:607-614.

17. Cao PP, Zhang YN, Liao B, et al. Increased local lgE production induced by common aeroallergens and phenotypic alteration of mast cells in Chinese eosinophilic, but not non-eosinophilic, chronic rhinosinusitis with nasal polyps. Clin Exp Allergy 2014:44:690-700.

18. Fan $Y P, X u$ G, Zuo KJ, et al. Detection of specific lgE of anti-staphylococcus aureus enterotoxins in nasal polyps and analysis theoretically about the superantigen hypothesis. Zhong hua Er Bi Yan Hou Tou Jing Wai Ke Za Zhi 2006;41:825-829.

19. Takeda K, Sakakibara S, Yamashita K, et al. Allergic conversion of protective mucosal immunity against nasal bacteria in chronic rhinosinusitis with nasal polyposis. J Allergy Clin Immunol. 2018 Jul 25. pii: S00916749(18)31057-1. 
20. Saitoh T, Kusunoki T, Yao T, et al. Relationship between epithelial damage or basement membrane thickness and eosinophilic infiltration in nasal polyps with chronic rhinosinusitis. Rhinology 2009;47:275-279.

21. Shi $L L$, Xiong $P$, Zhang $L$, et al. Features of airway remodeling in different types of Chinese chronic rhinosinusitis are associated with inflammation patterns. Allergy 2013:68:101-109.
Xiang Lu, M.D., Ph.D.

Associate professor of Otolaryngology

Head and Neck Surgery

Tongji Hospital

Tongji Medical College

Huazhong University of Science and
Technology

No.1095 Jiefang Avenue

Wuhan 430030

P.R.China

E-mail: luxiangent@hotmail.com 